\section{Vascular incontinence: incontinence in the elderly due to ischemic white matter changes}

\author{
Ryuji Sakakibara, 1 Jalesh Panicker, ${ }^{2}$ \\ Clare J Fowler,2 Fuyuki Tateno,1 \\ Masahiko Kishi,1 Yohei Tsuyuzaki, ${ }^{1}$ \\ Emina Ogawa, 1 Tomoyuki Uchiyama, ${ }^{3}$ \\ Tatsuya Yamamoto 3 \\ 1Neurology Department, Internal \\ Medicine, Sakura Medical Center, Toho \\ University, Sakura, Japan; \\ 2Uro-Neurology, the National Hospital \\ for Neurology and Neurosurgery, Queen \\ Square, London, UK; ${ }^{3}$ Neurology, Chiba \\ University, Chiba, Japan
}

\section{Abstract}

This review article introduces the new concept of vascular incontinence, a disorder of bladder control resulting from cerebral white matter disease (WMD). The concept is based on the original observation in 1999 of a correlation between the severity of leukoareosis or WMD, urinary symptoms, gait disorder and cognitive impairment. Over the last 20 years, the realization that WMD is not a benign incidental finding in the elderly has become generally accepted and several studies have pointed to an association between geriatric syndromes and this type of pathology. The main brunt of WMD is in the frontal regions, a region recognized to be crucial for bladder control. Other disorders should be excluded, both neurological and urological, such as normal-pressure hydrocephalus, progressive supranuclear palsy, etc., and prostatic hyperplasia, physical stress incontinence, nocturnal polyuria, etc Treatment involves management of small vessel disease risk factors and anticholinergic drugs that do not easily penetrate the blood brain barrier to improve bladder control.

\section{Incidence of incontinence in the elderly}

The incidence of urinary frequency/urgency (also called overactive bladder) with or without incontinence in the general population over 40 years in age is estimated to be $16.6 \%$ in Europe, ${ }^{1} 16.4 \%$ in the USA, ${ }^{2}$ and $12.4 \%$ in Asia (Japan). ${ }^{3}$ However, the prevalence increases significantly with age so that out of a population over 65 years old, $35-50 \%$ are affected ${ }^{3}$. It is now widely acknowledged that urinary, fre- quency and poor bladder control has a significant impact on quality of life and that bladder dysfunction in elderly people adds to career burden and is an important factor leading to institutionalization. ${ }^{4}$

Urinary incontinence in the elderly is a multifactorial disorder and, as with many such conditions in the elderly, it is principally due to a failure of compensation. ${ }^{5,6}$

\section{The cause of incontinence in the elderly: evolving concepts}

There is an important body of work which has used electron microscopy to examine ultrastructural details of the detrusor muscle and its innervation in the elderly in an attempt to identify specific morphological features which correlate with detrusor overactivity, detrusor hyocontractility and the disorder DIHC (detrusor instability and hypocontractility). ${ }^{7-12}$

Such findings provide a strong indication that a significant contribution to the problem of incontinence in the frail elderly is age-related changes in the bladder itself. The recent view that has emerged that there may also be an important cerebral vascular component is, therefore, quite novel but certainly warrants close attention. This new line of thinking started with a publication of Sakakibara et al., in 1999.13

Sakakibara et al. ${ }^{13}$ investigated 63 subjects, 28 male and 35 female, mean age 73 years, (range 62-86 years) demonstrated to have varying degrees of cerebral white matter disease or leuko-araiosis (Figure 1). ${ }^{13,14}$ Various clinical complaints were involved and included gait difficulty in 7, dysarthria in 5 and amnesia in 5 : none was bed-ridden. Eleven had history of single lacunar infarct, including mild hemiparesis or hemisensory disturbance. Magnetic resonance imaging-defined white matter changes were graded on a scale of 0 to 4, according to that of Brand-Zawadzki et al. 15 Urinary function was assessed by questionnaire and dysfunction graded as mild, with nocturnal urinary frequency of 2 or more and severe with urge urinary incontinence. Cognitive disorder was graded as mild with score below 24 and severe below 19 of mini-mental state examination (MMSE). Gait disorder was graded as mild with 1 feature and severe with 3 features of slowness of gait, shortstep/festination and loss of postural reflex.

The prevalence of nighttime urinary frequency in cases of grade 1 white matter changes was $60 \%, 58 \%$ in grade $2,93 \%$ in grade 3 , and $91 \%$ in grade 4 , respectively, giving an overall prevalence of nighttime urinary frequency of around $75 \%$. Similarly, urge urinary incontinence in grade 1 white matter change was $33 \%, 25 \%$ in grade $2,57 \%$ in grade 3 , and $45 \%$ in grade 4 , respectively, with an
Correspondence: Correspondence: Ryuji Sakakibara, Neurology Department, Internal Medicine, Sakura Medical Center, Toho University, 564-1 Shimoshizu, Sakura, 285-8741 Japan.

Tel. +81.434628811 - Fax: +81.434874246 .

E-mail: sakakibara@sakura.med.toho-u.ac.jp

Key words: geriatric incontinence, white matter change, overactive bladder, vascular incontinence.

Conflict of interests: the authors report no potential conflict of interests.

Received for publication: 22 August 2011. Revision received: 17 December 2011.

Accepted for publication: 16 January 2012.

This work is licensed under a Creative Commons Attribution NonCommercial 3.0 License (CC BYNC 3.0).

(C) Copyright R. Sakakibara et al., 2012

Licensee PAGEPress, Italy

Neurology International 2012; 4:e13

doi:10.4081/ni.2012.e13

overall prevalence of urge urinary incontinence in white matter changes estimated at around $40 \%$. Nocturnal urinary frequency was a more common and earlier feature than urinary incontinence (Figure 1).13 Of particular importance was the fact that urinary frequency, urgency with or without incontinence, was not always accompanied by gait disorder or dementia (Grade 1, Figure 1), so that it appeared that urinary frequency/urgency might be the first clinical manifestation of the observed white matter changes. ${ }^{13}$

Until around the time of Sakakibara's observations, white matter disease (WMD), variously described as white matter hyperintensities white matter change, white matter ischemia, multiple cerebral infarction of the white matter type, had been thought to be of little clinical relevance, and regarded as an incidental phenomenon in aging. The first pathological description of white matter changes in the aged brain dates back to Durand-Fardel in 1854, who named the condition atrophie interstitielle du cerveau (interstitial atrophy of the brain), and believed it to be asymptomatic. 16 Binswanger in 1894 described it pathologically as arteriosklerotische hirnerkrankung/ hirnatrophie (arteriosclerotic brain atrophy), since it is very likely that the subcortical loss of fibers is caused by the deficiency of the blood supply resulting from arteriosclerosis. 17 In 1987, Hachinski coined the name leukoaraiosis, which he derived from the Greek word leukos meaning white and araios meaning rarefied, in order to describe the radiological images of 
loss of density of the periventricular white matter observed by computed tomography (CT) scan. ${ }^{18}$ Advances in neuroimaging, particularly magnetic resonance imaging (MRI) at that time, enabled early recognition of white matter changes pathological to white matter rarefaction. ${ }^{19,20}$

\section{Geriatric syndromes and white matter disease}

Recent population-based MRI studies suggest that the incidence of moderate white matter lesions (periventricular white matter lesions grade $>4 / 9$ and subcortical white matter volume $>1.5 \mathrm{~mL}$ ) to be around $10 \%$ (7.6$24 \%$ ) in the general population over 55 years of age,,$^{21-23}$ comparable to that of type 2 diabetes. It is now recognized that WMD can develop into three different geriatric syndromes, e.g. i) vascular dementia: usually mild in the MiniMental State Examination and other general cognitive function, while the Frontal Assessment Battery might be low; ${ }^{24}$ hallucination and delusion are rare; sometimes stepwise deterioration; 25 in most advanced stages, emotional incontinence may occur; ii) vascular parkinsonism: gait disorder or easy falls, slow, short-stepped gait, often with wide-based gait, usually lacking apparent tremor and rigidity in the hands. ${ }^{26}$ It is otherwise called lower body parkinsonism and the gait disturbance may manifest as frontal gait apraxia, sometimes with frontal release signs (palmomental, snout, or grasping); in advanced stages, dysphagia and aspiration pneumonia may occur; and 3) following the paper of Sakakibara et al. 13 and since confirmed by others, ${ }^{27,28}$ vascular incontinence, i.e. urinary frequency/urgency with or without incontinence. These three features can present in any combination; howev-

Figure 1. Cerebral white-matter changes and urinary dysfunction. Schematic presentation of the grading of white-matter lesions on MRI: Grade 0, none. Grade 1, punctate foci with high signal intensity in the white matter immediately at the top of the frontal horns of the lateral ventricles. Grade 2, white-matter lesions were seen elsewhere but remained confined to the immediate subependymal region of the ventricles. Grade 3, periventricular as well as separate, discrete, deep white-matter foci of signal abnormality. Grade 4, discrete white-matter foci had become large and coalescent. Graphs: urinary dysfunction and whitematter lesions on MRI; cognitive disorder and white-matter lesion on MRI. MMSE: mini-mental state examination. Gait disorder and white-matter lesion on MRI. Reproduced with permission. 13
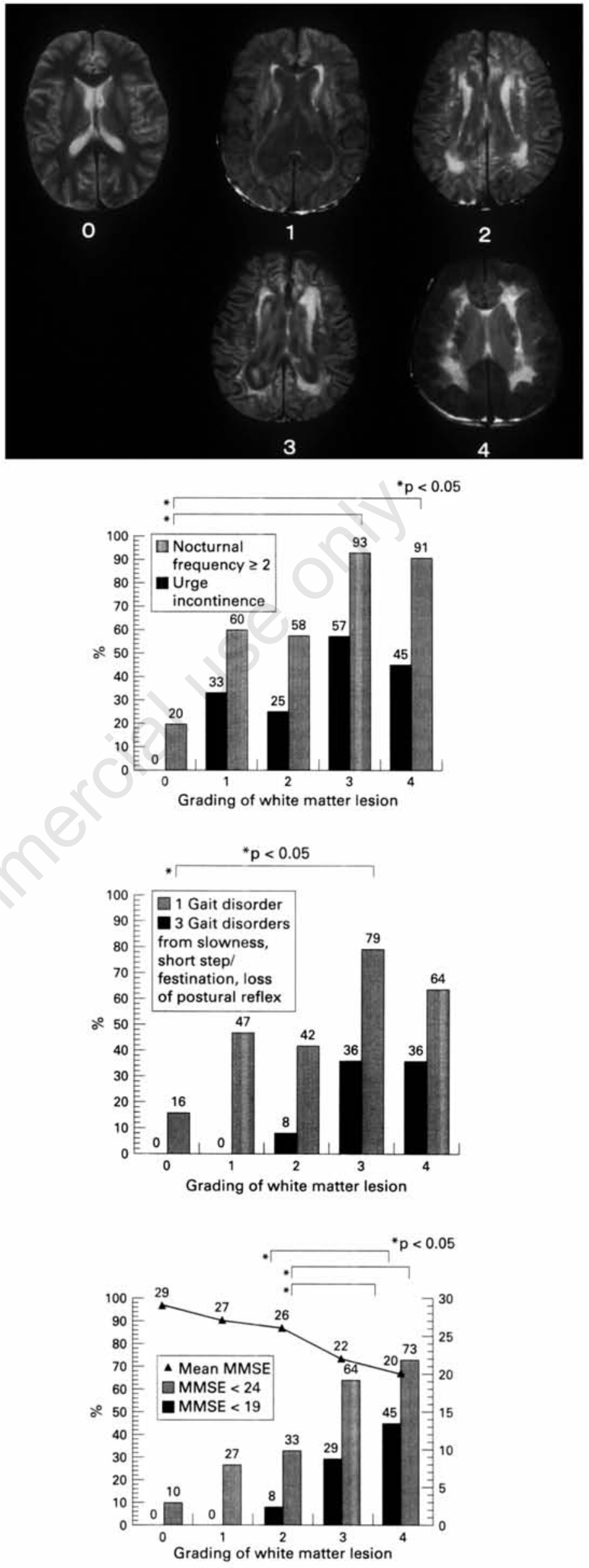

[Neurology International 2012; 4:e13]

[page 53] 
er, clinically, urinary and gait disorders are more prominent than dementia, and usually precede it.

\section{Pathology of white matter disease}

Diffuse abnormalities are seen in the small deep perforating vessels of the hemispheric white matter, basal ganglia and brain stem. These changes have been described as segmental arteriolar disorganisation by Miller Fisher and pathological changes range from lipohyalinosis to fibrinoid necrosis and disintegration of small vessels. Occlusion of these vessels results in hypoperfusion and ischemia. Atherosclerosis, the predominant pathological finding in large vessel disease, is an uncommon finding. ${ }^{29}$ Disruption of the blood brain barrier is likely to precipitate or worsen progression of WMD. ${ }^{30}$ Cerebral microbleeds (small, perviascular haemorrhages) are commonly seen. Small vessel disease may lead to loss of autoregulation of cerebral blood supply, which results in a higher susceptibility of white matter to undergo drops in blood flow during episodes of systemic hypotension. ${ }^{19,20}$ Recent positron emission tomography imaging with 18F-fluoromisonidazole showed higher susceptibility to ischemia of white matter than gray matter in stroke cases. 31,32

Although there is some debate, it is known that the incidence of white matter change significantly increases with atherosclerotic risk factors, e.g. hyperlipidemia, diabetes, obesity, metabolic syndrome, hypertension, ${ }^{21-23}$ cigarette smoking, carotid plaque, ${ }^{33}$ high cardioankle vascular stiffness index (CAVI), and gene polymorphism of aldosterone synthase, 34 angiotensinogen, angiotensin II type 1 receptor, ${ }^{35}$ nitric oxide synthase, ${ }^{35}$ and angiotensinconverting enzyme, 36 (hypertension), methylenetetrahydrofolate reductase gene (homocysteine metabolism), 37 matrix metalloproteinase3 and -9 genes (vascular remodeling), 38 fibrinogen gene (fibrin clot formation), ${ }^{39}$ genes of apolipoprotein E and Paraoxonase 1 (lipid metabolism), 40,41 and C-reactive protein gene (inflammation). ${ }^{42}$ Rare but well-established genetically transmitted white matter changes also exist: one is cerebral autosomal-dominant arteriopathy with subcortical infarcts and leukoencephalopathy (CADASIL) ${ }^{43}$ with NOTCH3 gene mutation (endoplasmic reticulum dysfunction), and the other is cerebral autosomal recessive arteriopathy with subcortical infarcts and leukoencephalopathy (CARASIL) $^{44}$ with high-temperature requirement A serine peptidase 1 (HTRA1) gene mutation (transforming growth factor -beta dysfunction). Experimental studies have suggested that other factors contributing to white matter changes include transient brain edema and blood-brain barrier damage. ${ }^{45-47}$

The incidence of white matter change significantly increases with age. ${ }^{21-23}$ White matter change slowly progresses after being identified; 48,49 and mildly increases the rate of newonset stroke (constituting a prodrome of future stroke). .50 White matter changes are rarely noted in subjects with transient ischemic attack (TIA), whereas they are common in small vessel ischemic stroke. ${ }^{51,52} \mathrm{~T} 2$ *weighted gradient-echo MRIs in subjects with white matter change sometimes show comorbid cerebral microbleeds. At present, the etiology of cerebral microbleeds includes atherosclerosis (seen in both the basal ganglia and subcortical area) ${ }^{14,53}$ and age-related amyloid angiopathy (in the subcortical area). Whether cerebral microbleeds alone present with clinical symptoms remains a matter of debate. ${ }^{54}$

\section{Cause of bladder dysfunction in white matter disease}

Detrusor overactivity is the major underlying pathophysiology of vascular incontinence. The incidence of detrusor overactivity in cases of white matter change is reported to be $70-91 \%$ of patients, 13,55 and is more common than following hemispheric stroke. 56 Detrusor overactivity is a urodynamic observation characterized by involuntary contractions during the filling phase which may be spontaneous or provoked. 57 In the study of Sakakibara et al. ${ }^{13}$ urodynamic studies were performed in 33 of the subjects, divided into 2 groups according to the above criteria (grade 0,11 elderly subjects as described above, 2 with nocturnal urinary frequency $\geq 2$ but no urge urinary incontinence, grade 1-4, 22 subjects, 14 male 8 female, mean age 72 years, 19 with nocturnal urinary frequency $\geq 2$ and 12 with urge urinary incontinence). They found that subjects with grade 1-4 white-matter lesion had detrusor overactivity more commonly $(82 \%)$ than those with grade 0 white-matter lesion $(9 \%)(I<0.05)$. Post-micturition residuals, low compliance, detrusor-sphincter dyssynergia and uninhibited sphincter relaxation were also more common in grade 1-4 white-matter lesion than in grade 0 white-matter lesion, though there was no statistical significance.

\section{Cerebral control of the bladder and how it is affected by white matter disease}

The frontal cortex is now recognized as an important the higher center for micturition: damage to the prefrontal cortex, medial supe- rior/middle frontal gyri, anterior cingulate cortex, supplemental motor area and insula have been shown to result in marked lower urinary tract dysfunction in humans. 56,58 These clinical observations have been corroborated by functional neuroimaging in humans.59-61 The connection between the prefrontal cortex and the micturition circuit is still uncertain, but it is known that the prefrontal cortex projects fibers directly to the hypothalamus-periaqueductal gray. The prefrontal-striatal pathway may also have a role. 62 Detrusor overactivity is considered to be an exaggerated spinobulbospinal micturition reflex that normally promotes micturition in brain lesions. ${ }^{63}$ Functional neuroimaging studies showed that the prefrontal cortex was deactivated in elderly subjects with urinary frequency/urgency as compared with controls. ${ }^{64}$

Cortical white matter change in MRI looks diffuse. However, within the brain, detailed pathology studies confirmed that the frontal lobe is most severely affected. 65 This is in line with the fact that MRI volumetry showed frontal lobe atrophy, 66 where glucose and $\mathrm{N}$ acetyl-aspartate metabolism was most severely reduced. 67,68 Corresponding to this, brain perfusion was most severely reduced in the frontal lobe of subjects with white matter change, ${ }^{69}$ a finding that must still be fully explained. However, in these patients, hypoxic-ischemic damage to oligodendrocytes was marked in the frontal lobe thus impairing not only the frontal micturition pathway, but also the frontal gait and cognitive pathways, relevant also to cerebrovascular parkinsonism and dementia. ${ }^{70-73}$

Based on a recognition of the importance of WMD in elderly and the new understanding of the cerebral control of micturition, Kuchel $e t$ $a l .27$ analyzed the location of white matter change and urinary dysfunction in 97 community-dwelling individuals (age 75-89 years). Baseline incontinence status and related symptoms were evaluated using validated instruments (3IQ, Urinary Incontinence Severity Index, Urogenital Distress Inventory, and Incontinence Impact Questionnaire). Regional white matter change was measured and analyzed using reference brain atlases [white matter parcelation atlas [WMPA] and the International Consortium on Brain Mapping (ICBM)]. They chose seven brain regions representing relevant white matter tracts: anterior corona radiata, inferior frontooccipital fasciculus, cingulate gyrus, cingulate hippocampal portion, superior frontooccipital fasciculus, uncinate fasciculus, and genu of the corpus callosum. These anterior regions are known to have a potential role in bladder control. The anterior corona radiata contains both descending prefrontal corticopontine projections and ascending thalamocortical (frontal/prefrontal) projections. Sixty-two (64\%) of the participants were incontinent, 

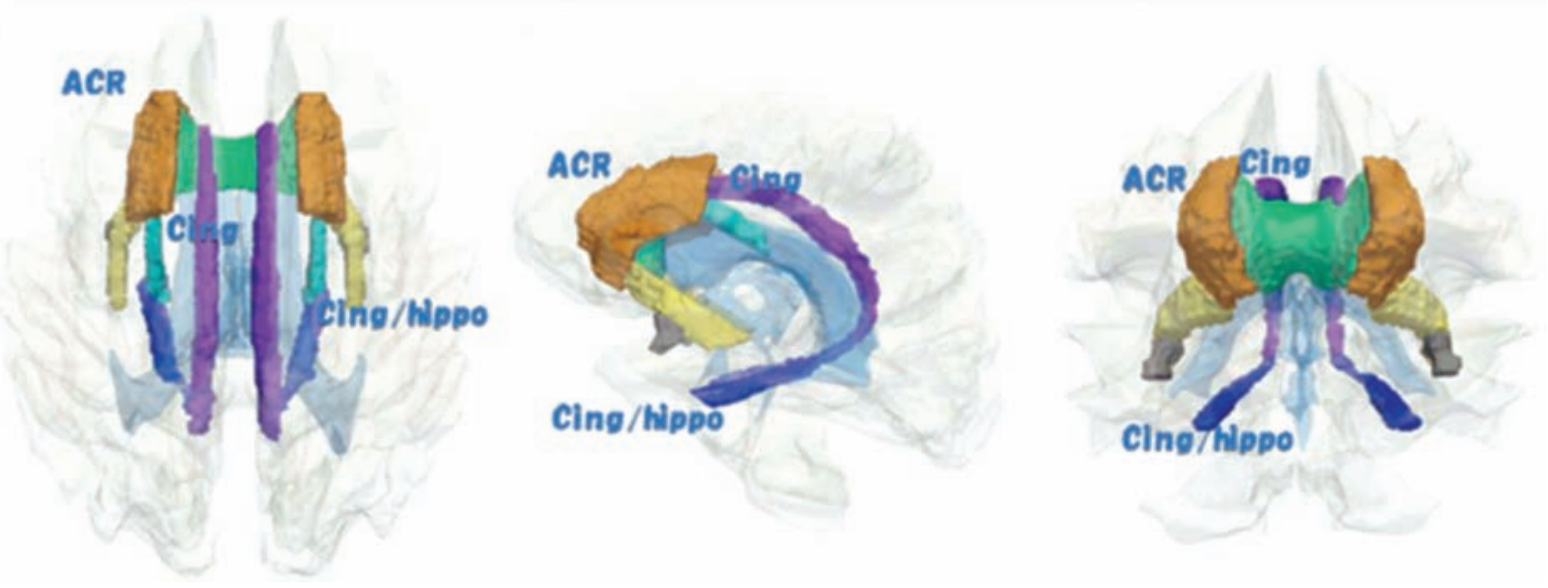

Figure 2. Cerebral white-matter changes and urinary dysfunction. The presence of white matter change in right inferior frontal regions and relevant tracts (anterior corona radiata and superior fronto-occipital fasciculus) is related with incontinence, incontinence severity, and degree of bother. ACR, Anterior corona radiata; Cing, Cingulate gyrus; Cing/hippo, Cingulate hippocampal portion. Reproduced with permission. 27

mostly with urgency $(\mathrm{n}=37,60 \%)$ and moderate-severe symptoms $(\mathrm{n}=36,58 \%)$. As a result, the presence of white matter change in the right frontal and right inferior frontal regions predicts incontinence severity, while no significant relationship was seen with incontinence, incontinence type, bother, or functional impact (Figure 2).27 As regards white matter-relevant tracts, white matter change that overlapped the anterior corona radiata predicted severity and a degree of disturbance, cingulate gyrus predicted incontinence and severity, whereas cingulate (hippocampal portion) and superior fronto-occipital fasciculus predicted severity. The same group reported that the volume of white matter change predicts executive function, mobility, and urinary incontinence. ${ }^{74}$

Most recently the Pittsburgh group studied 25 older women (age 71.5 \pm 7.5 years) with urgency incontinence. ${ }^{28}$ Mean MMSE score was 29.2 ; none had cognitive problems. In these patients, volume and location of white matter change, specific white matter tracts, and regional brain activity by fMRI during bladder filling and reported urgency were analyzed. As a result, brain responses to bladder filling during self-reported urgency were most prominent in the frontal regions, including medial/superior frontal gyrus adjacent to dorsal anterior cingulate gyrus (ACG) and other areas. Regional activations (e.g. medial/superior frontal gyrus adjacent to dorsal ACG) and deactivations (e.g. perigenual ACG adjacent to ventromedial prefrontal cortex) became more prominent with increased global white matter change (Figure 3). Looking at the fiber tracts within the white matter, e.g. anterior thalamic radiation (ATR), uncinate fasciculus (UNC), inferior fronto-occipital fasciculus (IFO), inferior longitudinal fasciculus (ILF) and superior longitudinal fasciculus (SLF), the main effect
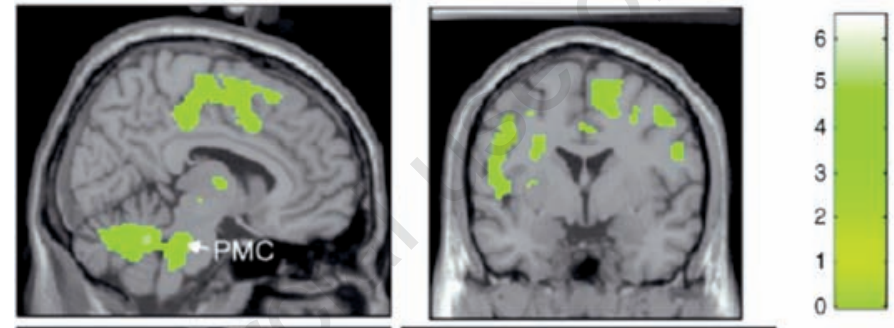

Global WMH Correlations

(a) positive
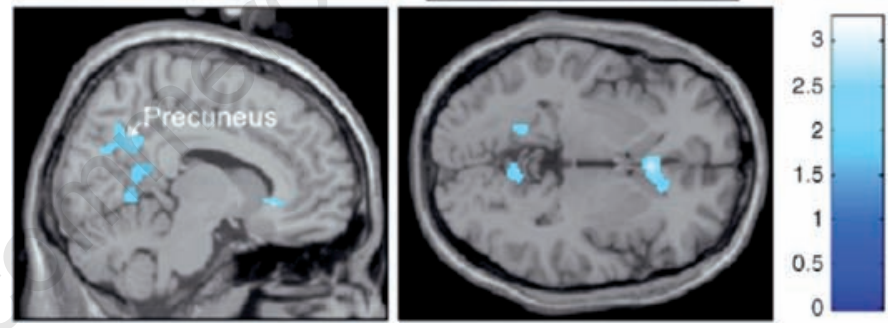

(b) negative

Figure 3. Cerebral white-matter changes and urinary dysfunction. Regional activations (e.g. medial/superior frontal gyrus adjacent to dorsal anterior cingulate gyrus, cerebellum and pontine micturition center [PMC]) have positive correlations with global white matter change (upper panel), while some regional activations (e.g. precuneus, etc.) have negative correlations. Reproduced with permission. ${ }^{28}$

activations and deactivations were superimposed with ATR (anterior, semi-horizontally projecting fibers to the medial prefrontal cortex and perigenual ACG, and also to several areas that were deactivated; $55 \%$ consisting of global white matter change) and SLF (middle, semi-vertically projecting fibers to dorsal ACG, insula, and inferior frontal gyrus; consisting of only $8 \%$ of global white matter change), respectively (Figure 3).28 The results indicated that the white matter changes, particularly the anterior portion that includes ATR, are clearly related with overactive bladder in cognitivelyintact, elderly women.

\section{Differential diagnosis}

Urological problems are an important cause for incontinence in the elderly. Detrusor overactivity may occur in men with benign prostatic enlargement. However, in 25-93\%, detrusor overactivity is reported to remain unchanged after prostatectomy, the figures increasing with age. ${ }^{75,76}$ Concomitant white matter changes are reported in this group by Sakakibara et al.77 and are likely to contribute to detrusor overactivity. Elderly women may present with stress incontinence, which can be differentiated by history. 
Diabetes, when uncontrolled, may manifest with overactive bladder symptoms due to polyuria. However detrusor overactivity is also seen and recent surveys suggest that diabetic neuropathy is often accompanied by white matter change, because of atherosclerosis in the cerebral arteries.78 In Kaplan's study of cases with diabetes, 79 there was a negative correlation between detrusor overactivity and features suggestive of sacral neuropathy (decrease in perineal sensation, sphincter tone, and bulbocavernosus reflex). In Rapidi's study of cases with diabetes, ${ }^{80}$ detrusor overactivity tended to parallel a prolonged central conduction time by somatosensory evoked potential, suggesting a central etiology. Nocturia may result from nocturnal polyuria (more than $33 \%$ of urine production during night-time) which can be detected by a bladder diary and may result from several medical conditions, such as chronic heart failure, chronic kidney dysfunction, postural hypotension partial pituitary diabetes insipidus and obstructive sleep apnea syndrome.

Other neurological conditions may also manifest with incontinence. Normal-pressure hydrocephalus (NPH) presents with a similar clinical triad as WMD, namely gait disorder, urinary incontinence, and dementia. ${ }^{81}$ However it is one-tenth as common as WMD. ${ }^{2}$ Brain imaging is essential to differentiate the two conditions. Bladder disorder in NPH mimics that in white matter change (detrusor overactivity, 95\%), ${ }^{83}$ presumably reflecting frontal lobe hypoperfusion. ${ }^{84}$ Importantly, bladder dysfunction and frontal lobe hypoperfusion in NPH can be reversed after shunt surgery. Other differential diagnoses include: for dementia, Alzheimer's disease (detrusor overactivity, 40\%);85 for gait disorder, Parkinson's disease (detrusor overactivity, 45-93\%);86 and for dementia and gait disorder, dementia with Lewy bodies (detrusor overactivity, $71 \%)^{87}$ and progressive supranuclear palsy (detrusor overactivity, $67 \%) .88$

\section{Treatment and prevention of vascular disease}

Though the vascular changes may not be reversible, early identification of risk factors and initiation of secondary prevention might arrest the disease progress. The results from studies exploring control of vascular risk factors, such as hypertension, ${ }^{89}$ dyslipidemia and diabetes, ${ }^{90,91}$ do not provide conclusive evidence. Falls in blood pressure may, in fact, worsen gait by counteracting the high-set cerebral autoregulation. ${ }^{89}$ The prevention of small vessel disease is controversial.
Antiplatelet medication for white matter change has been suggested; however, at present there are no large prospective studies available. On the other hand, there is a risk of hemorrhagic complication of antiplatelet drug use when there are comorbid microbleeds. ${ }^{92}$ Carotid endarterectomy improved cognitive function in one study in white matter changes accompanied by carotid stenosis. ${ }^{93}$ Although edaravone, a free radical scavenger, has begun to be used in acute ischemic stroke, its use in slowly progressive white matter change awaits further study. ${ }^{94}$ None of these studies have specifically studied improvement in bladder symptoms.

\section{Treatment of urinary frequency/urgency}

Medications used to treat vascular incontinence include anticholinergic agents, such as oxybutynin, propiverine, detrusitol, solifenacin,and imidafenacin. ${ }^{95}$ Mori et al. ${ }^{96}$ performed urodynamics in 46 dementia patients, and found detrusor overactivity in $91 \%$ of patients with white matter change and $58 \%$ of Alzheimer's patients. They conducted an open trial with $20 \mathrm{mg} /$ day of propiverine hydrochloride for two weeks irrespective of the presence of detrusor overactivity, and found increased bladder capacity or lessened frequency of incontinence in $40 \%$ of patients. Both groups responded almost equally, and patients with detrusor overactivity showed a more satisfactory response. Treatment for urinary frequency/urgency may be of particular benefit in subjects without marked immobility or dementia.

The use of medications with anticholinergic side-effects in the elderly is of concern, particularly when there is a risk of exacerbating cognitive impairment. Crossing the blood-brain barrier, they can act at the M1-muscarinic receptors in the cerebral cortex and hippocampus, or M4-receptors in the basal ganglia. Factors predisposing to cognitive side effects include: i) central muscarinic receptor affinity, e.g. high M1-receptor selectivity; and ii) permeability across the blood-brain barrier: size, lipid solubility, less number of hydrogen bonds, neutral or low degree of ionization and number of rotatable bonds. ${ }^{29,97,98}$ Darifenacin is an M3selective antagonist and thus has less cognitive side effects, while trospium, a quaternary amine, has a high polarity and, therefore, poor permeability across the blood-brain barrier. Other common anticholinergic side-effects are dryness of the mouth (M3) and constipation (M2,3). Extended-release formulations may lessen these adverse effects. ${ }^{99}$

\section{Conclusions}

Small vessel disease of the brain affecting the deep white matter characteristically manifests with neurological syndromes, such as vascular dementia and vascular Parkinsonism. There is, however, compelling evidence to suggest that white matter disease can also cause incontinence, and in some patients this may be the initial manifestation. Functional imaging studies have shown that anterior lesions, especially of the deep white matter of the frontal lobe, more often result in incontinence.

The pathophysiology basis for vascular incontinence is detrusor overactivity and management options are centered on the use of anticholinergics. Management of vascular risk factors is likely to arrest progression of vascular disease, but studies are required to evaluate whether this may improve incontinence.

\section{References}

1. Milsom I, Abrams P, Cardozo L, et al. How widespread are the symptoms of an overactive bladder and how are they managed? A population-based prevalence study. BJU International 2001;87:760-6.

2. Stewart WF, Van Rooyen JB, Cundiff GW, et al. Prevalence and burden of overactive bladder in the United States. World J Urol 2003;20:327-36.

3. Homma Y, Yamaguchi 0, Hayashi K; the Members of the Neurogenic Bladder Society Committee. An epidemiological survey of overactive bladder symptoms in Japan. BJU International 2005;96:1314-8.

4. Irwin DE, Milsom I, Kopp Z, et al. Impact of overactive bladder symptoms on employment, social interactions and emotional well-being in six European countries. BJU International 2005;97:96-100.

5 . Resnick NM. Urinary incontinence. Lancet 1995;346:94-9.

6. Rosenberg LJ, Griffiths DJ, Resnick NM. Factors that distinguish continent from incontinent older adults with detrusor overactivity. J Urol 2005;174:1868-72.

7. Elbadawi A, Hailemariam S, Yalla SV, Resnick NM. Structural basis of geriatric voiding dysfunction. VII. Prospective ultrastructural/urodynamic evaluation of its natural evolution. J Urol 1997;157:1814-22.

8. Elbadawi A, Hailemariam S, Yalla SV, Resnick NM. Structural basis of geriatric voiding dysfunction. VI. Validation and update of diagnostic criteria in 71 detrusor biopsies. J Urol. 1997;157:1802-13.

9. Elbadawi A, Yalla SV, Resnick NM. Structural basis of geriatric voiding dysfunction. IV. Bladder outlet obstruction. J 
Urol 1993;150:1681-95.

10. Elbadawi A, Yalla SV, Resnick NM. Structural basis of geriatric voiding dysfunction. III. Detrusor overactivity. J Urol 1993;150:1668-80.

11. Elbadawi A, Yalla SV, Resnick NM. Structural basis of geriatric voiding dysfunction. II. Aging detrusor: normal versus impaired contractility. J Urol 1993;150: 1657-67.

12. Elbadawi A, Yalla SV, Resnick NM. Structural basis of geriatric voiding dysfunction. I. Methods of a prospective ultrastructural/urodynamic study and an overview of the findings. J Urol 1993;150: 1650-6.

13. Sakakibara R, Hattori T, Uchiyama T, Yamanishi T. Urinary function in the elderly with and without leukoaraiosis; in relation to cognitive and gait function. $\mathrm{J}$ Neurol Neurosurg Psychiatry 1999;67:65860.

14. Werring DJ, Frazer DW, Coward LJ, et al. Cognitive dysfunction in patients with cerebral microbleeds on T2*-weighted gradient-echo MRI. Brain 2004;127:2265-75.

15. Brant-Zawadzki M, Fein G, Van Dyke C, et al. MR imaging of the aging brain; pacthy white-matter lesions and dementia. AJNR 1985;6:675-82.

16. Roman GC. On the history of lacunes, etat criblé, and the white matter lesions of vascular dementia. Cerebrovasc Dis 2002;13: 1-6.

17. Binswanger 0. Die Abgrenzung der allgemeinen progressiven Paralyse. Berl Klin Wochenschr 1894;31:1103-86.

18. Hachinski VC, Potter P, Merskey H. Leukoaraiosis. Arch Neurol 1987;44:21-3.

19. Fazekas F, Schmidt R, Kleinert R, et al. The spectrum of age-associated brain abnormalities: their measurement and histopathological correlates. J Neural Transm Suppl 1998;53:31-9.

20. Enzinger C, Fazekas F, Ropele S, Schmidt R. Progression of cerebral white matter lesions - Clinical and radiological considerations. J Neurol Sci 2007;257:5-10.

21. de Leeuw FE, de Groot JC, Oudkerk M, et al. Hypertension and cerebral white matter lesions in a prospective cohort study. Brain 2002;125:765-72.

22. Sierra C, de La Sierra A, Mercader J, et al. Silent cerebral white matter lesions in middle-aged essential hypertensive patients. J Hypertension 2002;20:519-24.

23. van Dijk EJ, Breteler MMB, Schmidt R, et al; for the CASCADE Consortium. The association between blood pressure, hypertension, and cerebral white matter lesions cardiovascular determinants of dementia study. Hypertension 2004;44: 625-30.

24. Erkinjuntti T, Gauthier S. The concept of vascular cognitive impairment. Front Neurol Neurosci 2009;24:79-85.

25. Wade J, Hachinski V. Revised ischemic score for diagnosing multi-infarct dementia. J Clin Psychiatry 1986;47:437-8.

26. Rektor I, Rektorova I, Kubova D. Vascular parkinsonism-an update. J Neurol Sci 2006; 248:185-91.

27. Kuchel GA, Moscufo N, Guttmann CR, et al. Localization of brain white matter hyperintensities and urinary incontinence in community-dwelling older adults. J Gerontol A Biol Sci Med Sci 2009;64:902-9.

28. Tadic SD, Griffiths D, Murrin A, et al. Brain activity during bladder filling is related to white matter structural changes in older women with urinary incontinence. Neuroscience 2010;51:1294-302.

29. Mazighi M, Labreuche J, Gongora-Rivera F, Duyckaerts C, Hauw JJ, Amarenco JP. Autopsy prevalence of intracranial atherosclerosis in patients with fatal stroke. Stroke 2008;39:1142-7.

30. Wardlaw JM. Blood-brain barrier and cerebral small vessel disease. J Neurol Sci 2010;299: 66-71.

31. Falcao ALE, Reutens DC, Markus R, et al. The resistance to ischemia of white and gray matter after stroke. Ann Neurol 2004;56:695-701.

32. Lee ST, Scott AM. Hypoxia positron emission tomography imaging with 18F-fluoromisonidazole. Semin Nucl Med 2007;37: 451-61.

33. Patterson AJ, U-King-Im JM, Tang TY, et al. Association between white matter ischaemia and carotid plaque morphology as defined by high-resolution in vivo MRI. Eur J Vasc Endovasc Surg 2009;38:149-54.

34. Verpillat P, Alpérovitch A, Cambien F, et al. Aldosterone synthase (CYP11B2) gene polymorphism and cerebral white matter hyperintensities. Neurology 2001;56:6735.

35. Henskens LH, Kroon AA, van Boxtel MP, et al. Associations of the angiotensin II type 1 receptor $\mathrm{A} 1166 \mathrm{C}$ and the endothelial NO synthase G894T gene polymorphisms with silent subcortical white matter lesions in essential hypertension. Stroke 2005;36: 1869-73.

36. Purandare N, Oude Voshaar RC, Davidson $\mathrm{Y}$, et al. Deletion/insertion polymorphism of the angiotensin-converting enzyme gene and white matter hyperintensities in dementia: A pilot study. J Am Geriatr Soc 2006;54:1395-400.

37. Kohara K, Fujisawa M, Ando F, et al; NILSLSA Study. MTHFR gene polymorphism as a risk factor for silent brain infarcts and white matter lesions in the Japanese general population: The NILS-LSA Study. Stroke 2003;34:1130-5.

38. Fornage M, Mosley TH, Jack CR, et al.
Family-based association study of matrix metalloproteinase-3 and -9 haplotypes with susceptibility to ischemic white matter injury. Hum Genet 2007;120:671-80.

39. van Oijen M, Cheung EY, Geluk CE, et al. Haplotypes of the fibrinogen gene and cerebral small vessel disease: the Rotterdam scan study. J Neurol Neurosurg Psychiatry 2008;79:799-803.

40. Schmidt R, Schmidt H, Fazekas F, et al. Apolipoprotein E polymorphism and silent microangiopathy-related cerebral damage. Results of the Austrian Stroke Prevention Study. Stroke 1997;28:951-6.

41. Schmidt R, Schmidt H, Fazekas F, et al. MRI cerebral white matter lesions and paraoxonase PON1 polymorphisms : threeyear follow-up of the austrian stroke prevention study.Arterioscler Thromb Vasc Biol 2000;20:1811-6.

42. Reitz C, Berger K, de Maat MP, et al. CRP gene haplotypes, serum CRP, and cerebral small-vessel disease: the Rotterdam Scan Study and the MEMO Study. Stroke 2007; 38:2356-9.

43. Joutel A, Corpechot C, Ducros A, et al. Notch3 mutations in cerebral autosomal dominant arteriopathy with subcortical infarcts and leukoencephalopathy (CADASIL), a mendelian condition causing stroke and vascular dementia. Ann NY Acad Sci 1997;826:213-7.

44. Hara K, Shiga A, Fukutake T, et al. Association of HTRA1 mutations and familial ischemic cerebral small-vessel disease. New Eng J Med 2009;360:1729-39.

45. Moseley ME, Nishimura MC, Pitts LH, et al. Proton nuclear magnetic resonance spectroscopy of normal and edematous brain tissue in vitro: changes in relaxation during tissue storage. Magn Reson Imaging 1984;2:205-9.

46. Wallin A, Sjogren M, Edman A, et al. Symptoms, vascular risk factors and bloodbrain barrier function in relation to CT white-matter changes in dementia. Eur Neurol 2000;44:229-35.

47. Pantoni L. Pathophysiology of age-related cerebral white matter changes. Cerebrovasc Dis 2002;13:7-10.

48. Sachdev P, Wen W, Chen X, Brodaty H. Progression of white matter hyperintensities in elderly individuals over 3 years. Neurology 2007;68;214-22.

49. Enzinger C, Fazekas F, Ropele S, Schmidt R. Progression of cerebral white matter lesions - clinical and radiological considerations. J Neurol Sci 2007;257:5-10.

50. Gouw AA, van der Flier WM, Fazekas F, et al; LADIS Study Group. Progression of white matter hyperintensities and incidence of new lacunes over a 3-year period: the Leukoaraiosis and Disability study. Stroke 2008;39:1414-20. 
51. Rost NS, Fitzpatrick K, Biffi A, et al. White matter hyperintensity burden and susceptibility to cerebral ischemia. Stroke 2010;41:2807-11.

52. Rost NS, Rahman RM, Biffi A, et al. White matter hyperintensity volume is increased in small vessel stroke subtypes. Neurology 2010;75:1670-7.

53. Wardlaw JM, Lewis SC, Keir SL, et al. Cerebral microbleeds are associated with lacunar stroke defined clinically and radiologically, independently of white matter lesions. Stroke 2006;37:2633-6.

54. Tatsumi S, Shinohara M, Yamamoto T. Direct comparison of histology of microbleeds with postmortem MR images a case report. Cerebrovasc Dis 2008;26:142-6.

55. Sakakibara R, Hattori T, Tojo M. Micturitional disturbance in patients with cerebrovascular dementia. Autonom Nerv Syst 1993;30:390-6.

56. Sakakibara R, Hattori T, Yasuda K, Yamanishi T. Micturitional disturbance after acute hemispheric stroke: analysis of the lesion site by CT and MRI. JNeurol Sci 1996;137:47-56.

57. Abrams P, Cardozo L, Fall M, et al; Standardisation Sub-committee of the International Continence Society. The standardization of terminology of lower urinary tract function: report from the standardization sub-committee of the International Continence Society. Neurourol Urodynam 2002;21:167-78.

58. Andrew J, Nathan PW. Lesions of the anterior frontal lobes and disturbances of micturition and defaecation. Brain 1964;87: 233-62.

59. DasGupta R, Kavia RB, Fowler CJ. Cerebral mechanisms and voiding function. BJU Int 2007;99:731-4.

60. Sakakibara R, Tsunoyama K, Takahashi 0, et al. Real-time measurement of oxyhemoglobin concentration changes in the frontal micturition area: an fNIRS study. Neurourol Urodyn 2010;29:757-64.

61. Fowler CJ, Griffiths DJ. A decade of functional brain imaging applied to bladder control. Neurourol Urodyn 2010;29:49-55.

62. Herzog J, Weiss PH, Assmus A, et al. Improved sensory gating of urinary bladder afferents in Parkinson's disease following subthalamic stimulation. Brain 2008;131:132-45.

63. Fowler CJ, Griffiths D, de Groat WC. The neural control of micturition. Nat Rev Neurosci 2008;9:453-66.

64. Griffiths D, Tadic SD. Bladder control, urgency, and urge incontinence: evidence from functional brain imaging. Neurourol Urodyn 2008;27:466-74.

65. Hentschel F, Damian M, Krumm B, Froelich L. White matter lesions-ageadjusted values for cognitively healthy and demented subjects. Acta Neurol Scand 2007;115:174-80.

66. Mok V, Wong KK, Xiong Y, Wong A, Schmidt R, Chu W, Hu X, Leung EY, Chen S, Chen Y, Tang WK, Chen X, Ho CL, et al. Cortical and frontal atrophy are associated with cognitive impairment in age-related confluent white-matter lesion. J Neurol Neurosurg Psychiatry 2011;82:52-7.

67. Tullberg M, Fletcher E, DeCarli C, et al. White matter lesions impair frontal lobe function regardless of their location. Neurology 2004;63:246-53.

68. Schuff N, Capizzano AA, Du AT, et al. Different patterns of $\mathrm{N}$-acetylaspartate loss in subcortical ischemic vascular dementia and AD. Neurology 2003;61:35864.

69. Hanyu H, Shimuzu S, Tanaka Y, et al. Cerebral blood flow patterns in Binswanger's disease: a SPECT study using three-dimensional stereotactic surface projections. J Neurol Sci 2004;220:7984.

70. Baloh RW, Yue Q, Socotch TM, Jacobson KM. White matter lesions and dysequilibrium in older people; 2 . clinicopathological correlation. Arch Neurol 1995;52:975-81.

71. Yamanouchi H, Nagura H. Neurological signs and frontal white matter lesions in vascular parkinsonism. A clinicopathologic study. Stroke 1997;28:965-9.

72. Mok VC, Wong A, Yim P, et al. The validity and reliability of chinese frontal assessment battery in evaluating executive dysfunction among Chinese patients with small subcortical infarct. Alzheimer Dis Assoc Disord 2004;18:68-74.

73. Mok VC, Wong A, Wong K, et al. Executive dysfunction and left frontal white matter hyperintensities are correlated with neuropsychiatric symptoms in stroke patients with confluent white matter hyperintensities. Dement Geriatr Cogn Disord 2010;30: 254-60.

74. Wakefield DB, Moscufo N, Guttmann CR, et al. White matter hyperintensities predict functional decline in voiding, mobility, and cognition in older adults. J Am Geriatr Soc 2010;58:275-81.

75. Gormley EA, Griffiths DJ, McCracken PN, et al. Effect of transurethral resection of the prostate on detrusor instability and urge incontinence in elderly males. Neurourol Urodyn 1993;12:445-53.

76. Gormley EA, Griffiths DJ, McCracken PN, et al. Effect of transurethral resection of the prostate on detrusor instability and urge incontinence in elderly males. Neurourol Urodyn 1993;12:445-53.

77. Sakakibara R, Hamano S, Uchiyama T, et al. Do BPH patients have neurogenic detrusor dysfunction? A uro-neurological assessment. Urol Int 2005;74:44-50.
78. Yamaguchi C, Sakakibara R, Uchiyama T, et al. Overactive bladder in diabetes: a peripheral or central mechanism? Neurourol Urodyn 2007;26:807-13.

79. Kaplan SA, Te AE, Blaivas JG. Urodynamic findings in patients with diabetic cystopathy. J Urol 1995;153:342-4.

80. Rapidi CA, Karadreas N, Katsifotis C, et al. A combined urodynamic and electrophysiological study of diabetic cystopathy. Neurourol Urodynam 2005;24:1-7.

81. Adams RD, Fisher CM, Hakim S, et al. Symptomatic occult hydrocephalus with 'normal' cerebrospinal pressure. N Eng J Med 1965;273:117-26.

82. Hiraoka K, Meguro K, Mori E. Prevalence of idiopathic normal-pressure hydrocephalus in the elderly population of a Japanese rural community. Neurol Med Chir 2008;48:197-9.

83. Sakakibara R, Kanda T, Sekido T, et al. Mechanism of bladder dysfunction in idiopathic normal pressure hydrocephalus. Neurourol Urodyn 2008;27:507-10.

84. Sasaki H, Ishii K, Kono A, et al. Cerebral perfusion pattern of idiopathic normal pressure hydrocephalus studied by SPECT and statistical brain mapping. Ann Nucl Med 2007;21:39-45.

85. Sugiyama T, Hashimoto K, Kiwamoto $\mathrm{H}$, et al. Urinary incontinence in senile dementia of the Alzheimer type (SDAT). Int J Urol 1994;1:337-40.

86. Sakakibara R, Uchiyama T, Yamanishi T, Kishi M. Genitourinary dysfunction in Parkinson's disease. Mov Disord 2010;25: 2-12.

87. Sakakibara R, Ito T, Uchiyama $\mathrm{T}$, et al. Lower urinary tract function in dementia of Lewy body type (DLB). J Neurol Neurosurg Psychiatry 2005;76:729-32.

88. Sakakibara R, Hattori T, Tojo M, et al. Micturitional disturbance in progressive supranuclear palsy. J Auton Nerv Syst 1993;45:101-6.

89. Nagai M, Hoshide S, Kario K. Hypertension and dementia. Am J Hypertens 2010;23:11624.

90. Duron E, Hanon 0. Vascular risk factors, cognitve decline, and dementia. Vascular Health and Risk Management 2008:4:36381.

91. Cukierman-Yaffe T, Gerstein HC, Williamson JD, et al; ACCORDMIND Investigators. Relationship between baseline glycemic control and cognitive function in individuals with type 2 diabetes and other cardiovascular risk factors. The Action to Control Cardiovascular Risk in Diabetes-Memory in Diabetes (ACCORDMIND) trial. Diabetes Care 2009;32:221-6.

92. Gregoire SM, Jager HR, Yousry TA, et al. Brain microbleeds as a potential risk factor for antiplatelet-related intracerebral 
haemorrhage: hospital-based, case-control study. J Neurol Neurosurg Psychiatry 2010;81:679-84.

93. Borroni B, Tiberio G, Bonardelli S, et al. Is mild vascular cognitive impairment reversible? Evidence from a study on the effect of carotid endarterectomy. Neurol Res 2004;26:594-7.

94. Lapchak PA. A critical assessment of edaravone acute ischemic stroke efficacy trials: is edaravone an effective neuroprotective therapy? Expert Opin 2010;11:1753-63.

95. Homma Y, Yamaguchi 0; for the Imidafenacin Study Group. A randomized, double-blind, placebo- and propiverinecontrolled trial of the novel antimuscarinic agent imidafenacin in Japanese patients with overactive bladder. Int $\mathrm{J}$ Urol 2009;16:499-506.

96. Mori S, Kojima M, Sakai Y, Nakajima K. Bladder dysfunction in dementia patients showing urinary incontinence; evaluation with cystometry and treatment with propiverine hydrochloride. Jpn J Geriat 1999;36:489-94.

97. Scheife R, Takeda M. Central nervous system safety of anticholinergic drugs for the treatment of overactive bladder in the eld- erly. Clin Ther 2005;27:144-53.

98. Sakakibara R, Uchiyama T, Yamanishi T, Kishi M. Dementia and lower urinary dysfunction: with a reference to anticholinergic use in elderly population. Int $\mathrm{J}$ Urol 2008;15:778-88

99. Chu FM, Dmochowski RR, Lama DJ, et al. Extended-release formulations of oxybutynin and tolterodine exhibit similar central nervous system tolerability profiles: A subanalysis of data from the OPERA trial. Am J Obstet Gynecol 2005;192:1849-55. 